\title{
Seroprevalence of anti-SARS-CoV-2 antibodies 6 months into the vaccination campaign in Geneva, Switzerland, 1 June to 7 July 2021
}

Silvia Stringhini ${ }^{1,2,3}$, María-Eugenia Zaballa ${ }^{1}$, Nick Pullen ${ }^{1}$, Javier Perez-Saez ${ }^{1,4,5}$, Carlos de Mestral $^{1,3}$, Andrea Jutta Loizeau ${ }^{1}$, Julien Lamour ${ }^{1}$, Francesco Pennacchio ${ }^{1}$, Ania Wisniak ${ }^{1,5}$, Roxane Dumont ${ }^{1}$, Hélène Baysson ${ }^{1,2}$, Viviane Richard ${ }^{1}$, Elsa Lorthe ${ }^{1}$

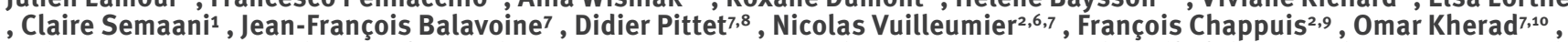
Andrew S. Azman ${ }^{1,4,5}$, Klara Posfay-Barbe ${ }^{7,11}$, Laurent Kaiser ${ }^{6,7,12}$, Idris Guessous ${ }^{2,9}$, on behalf of the Specchio-COVID19 study group ${ }^{13}$

1. Unit of Population Epidemiology, Division of Primary Care Medicine, Geneva University Hospitals, Geneva, Switzerland

2. Department of Health and Community Medicine, Faculty of Medicine, University of Geneva, Geneva, Switzerland

3. University Centre for General Medicine and Public Health, University of Lausanne, Lausanne, Switzerland

4. Department of Epidemiology, Johns Hopkins Bloomberg School of Public Health, Baltimore, Maryland, United States

5. Institute of Global Health, Faculty of Medicine, University of Geneva, Geneva, Switzerland

6. Division of Laboratory Medicine, Geneva University Hospitals, Geneva, Switzerland

7. Department of Medicine, Faculty of Medicine, University of Geneva, Geneva, Switzerland

8. Infection Control Program and World Health Organization Collaborating Centre on Patient Safety, Geneva University Hospitals, Geneva, Switzerland

9. Division and Department of Primary Care Medicine, Geneva University Hospitals, Geneva, Switzerland

10. Division of Internal Medicine, Hôpital de la Tour, Geneva, Switzerland

11. Department of Woman, Child, and Adolescent Medicine, Geneva University Hospitals, Geneva, Switzerland

12. Geneva Centre for Emerging Viral Diseases and Laboratory Virology, Geneva University Hospitals, Geneva, Switzerland

13. The members of this group are acknowledged at the end of the article

Correspondence: Silvia Stringhini (silvia.stringhini@hcuge.ch)

Citation style for this article:

Stringhini Silvia, Zaballa María-Eugenia, Pullen Nick, Perez-Saez Javier, de Mestral Carlos, Loizeau Andrea Jutta, Lamour Julien, Pennacchio Francesco, Wisniak

Stringhini Silvia, Zaballa María-Eugenia, Pullen Nick, Perez-Saez Javier, de Mestral Carlos, Loizeau Andrea Jutta, Lamour Julien, Pennacchio Francesco, Wisniak
Ania, Dumont Roxane, Baysson Hêlène, Richard Viviane, Lorthe Elsa, Semaani Claire, Balavoine Jean-François, Pittet Didier, Vuilleumier Nicolas, Chappuis François, Kherad Omar, Azman Andrew S., Posfay-Barbe Klara, Kaiser Laurent, Guessous Idris, on behalf of the Specchio-COVID19 study group. Seroprevalence of anti-

SARS-CoV-2 antibodies 6 months into the vaccination campaign in Geneva, Switzerland, 1 June to 7 July 2021. Euro Surveill. 2021;26(43):pii=2100830. https://doi. org/10.2807/1560-7917.ES.2021.26.43.2100830

Background: Up-to-date seroprevalence estimates are critical to describe the SARS-CoV-2 immune landscape and to guide public health decisions. Aim: We estimate seroprevalence of anti-SARS-CoV-2 antibodies 15 months into the COVID-19 pandemic and 6 months into the vaccination campaign. Methods: We conducted a population-based cross-sectional serosurvey between 1 June and 7 July 2021, recruiting participants from age- and sex-stratified random samples of the general population. We tested participants for anti-SARS-CoV-2 antibodies targeting the spike $(\mathrm{S})$ or nucleocapsid $(\mathrm{N})$ proteins using the Roche Elecsys immunoassays. We estimated the anti-SARSCoV-2 antibodies seroprevalence following vaccination and/or infection (anti-S antibodies), or infection only (anti-N antibodies). Results: Among 3,355 individuals (54.1\% women; $20.8 \%$ aged $<18$ years and $13.4 \%$ aged $\geq 65$ years), $2,161(64.4 \%)$ had anti-S antibodies and $906(27.0 \%)$ had anti-N antibodies. The total seroprevalence was $66.1 \%$ (95\% credible interval (Crl): 64.1-68.0). We estimated that $29.9 \%$ (95\% Crl: 28.0-31.9) of the population developed antibodies after infection; the rest having developed antibodies via vaccination. Seroprevalence estimates differed markedly across age groups, being lowest among children aged $0-5$ years (20.8\%; 95\% Crl: 15.5-26.7) and highest among older adults aged $\geq 75$ years (93.1\%; 95\% Crl: 89.6-96.0). Seroprevalence of antibodies developed via infection and/or vaccination was higher among participants with higher educational level. Conclusion: Most of the population has developed anti-SARS-CoV-2 antibodies, despite most teenagers and children remaining vulnerable to infection. As the SARS-CoV-2 Delta variant spreads and vaccination rates stagnate, efforts are needed to address vaccine hesitancy, particularly among younger individuals and to minimise spread among children.

\section{Introduction}

The Delta variant (Phylogenetic Assignment of Named Global Outbreak (Pango) lineage designation B.1.617.2) of the severe acute respiratory syndrome coronavirus 2 (SARS-CoV-2) drives a surge in new infections worldwide [1]. At the same time, vaccination rates stagnate in much of Europe [2], undermining efforts to achieve population immunity and curb the pandemic. Up-todate seroprevalence estimates of anti-SARS-CoV-2 antibodies in the general population remain scarce, 
Timeframe of serosurveys and COVID-19 vaccination campaign in Geneva, Switzerland, April 2020-August 2021

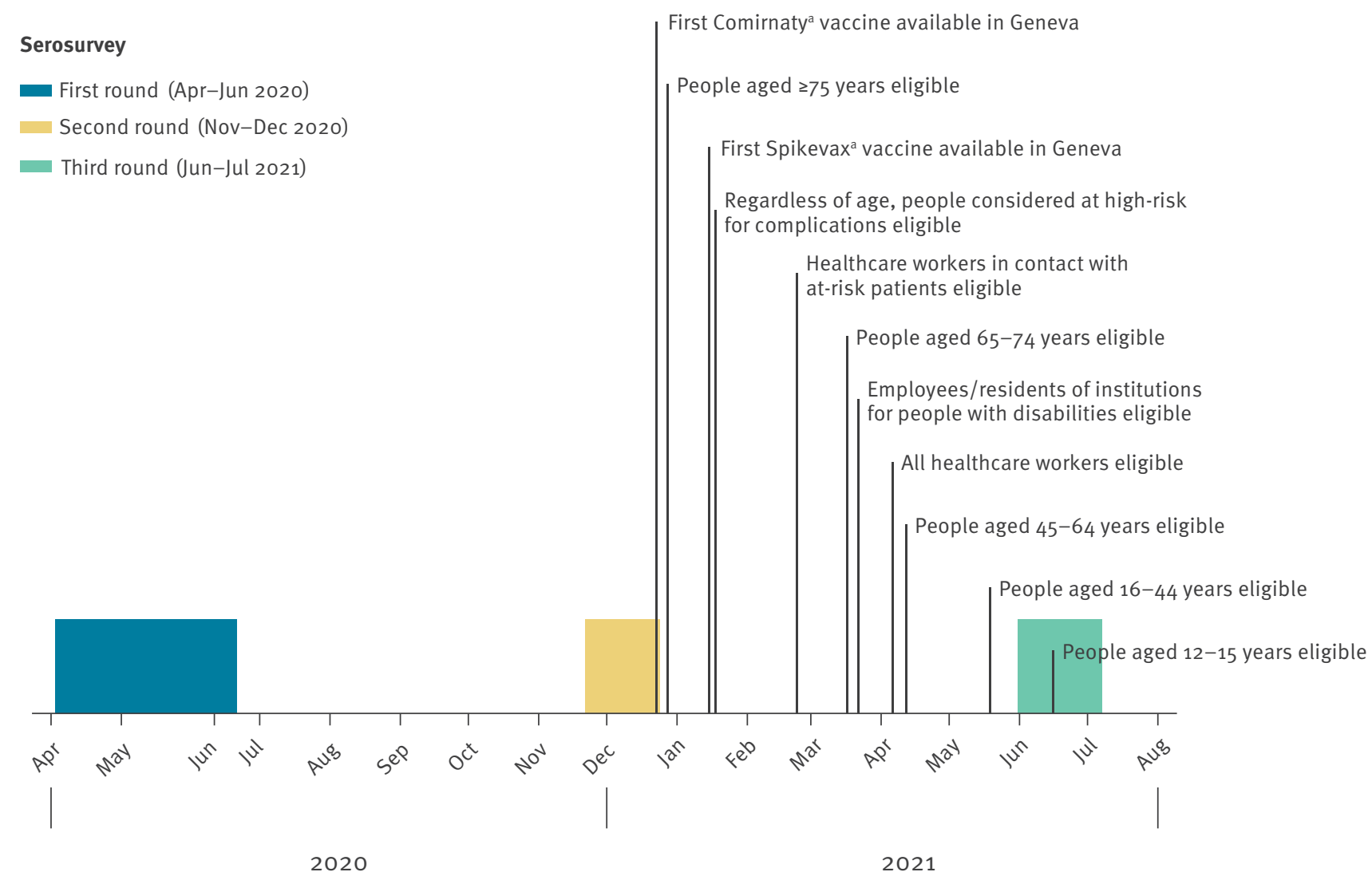

Date

COVID-19: coronavirus disease.

a During the course of the three surveys (April 2020-July 2021), the two vaccines approved for use in Switzerland were Comirnaty (BNT162b2, mRNA BioNTech-Pfizer, Mainz, Germany/New York City, United States (US)) and Spikevax (mRNA-1273, Moderna, Cambridge, US) [14].

Eligibility to receive the vaccine allowed individuals to register for an appointment to receive the first vaccine dose.

yet they are critical in monitoring the SARS-CoV-2 immune landscape in the population and guide public health decisions [3]. The state of Geneva, Switzerland, with a population of about 500,000, has been heavily affected by the pandemic, with 64,531 confirmed cases (127 per 1,000 inhabitants) and 748 deaths reported as at 27 August 2021 [4]. Previous serosurveys of the Geneva population revealed that one in 10 individuals had developed anti-SARS-CoV-2 antibodies by AprilJune 2020 following infection and two in 10 individuals had done so by November-December 2020 [5], before mass vaccination began.

The vaccination campaign began in Geneva on 28 December 2020. Initially only adults aged $\geq 75$ years were eligible; in subsequent weeks, eligibility to receive the vaccine expanded to individuals with high risk of COVID-19-related complications, healthcare workers and progressively to younger age groups until reaching the 12-15-year-olds (Figure 1). During the course of this study, the only two vaccines approved for use in Switzerland were the Comirnaty (BNT162b2,
mRNA, BioNTech-Pfizer, Mainz, Germany/New York City, United States (US)) and the Spikevax (mRNA-1273, Moderna, Cambridge, US).

To our best knowledge, the only serosurvey conducted after the third wave of the COVID-19 pandemic in a general population reported a total anti-SARS-CoV-2 antibodies seroprevalence of $17.3 \%$ in the Portuguese population up to March 2021 [6]. While they presented seroprevalence across three broad age categories, the study included no disaggregation of seroprevalence by sex or socioeconomic indicators, and its methodology did not allow distinguishing between antibodies developed following vaccination and/or infection and antibodies developed following infection only.

Using a representative sample of the general population, we aimed to assess the seroprevalence of anti-SARS-CoV-2 antibodies 15 months after the first confirmed case in Switzerland (26 February 2020) and 6 months after the vaccination campaign began. 
Sociodemographic characteristics of study participants, serological results and seroprevalence estimates, Geneva, Switzerland, 1 June-7 July $2021(\mathrm{n}=3,355)$

\begin{tabular}{|c|c|c|c|c|c|c|c|c|c|c|c|c|c|}
\hline \multirow{2}{*}{\multicolumn{2}{|c|}{ Characteristics }} & \multirow{2}{*}{\multicolumn{2}{|c|}{ Participants }} & \multirow{2}{*}{\multicolumn{2}{|c|}{$\begin{array}{c}\text { Vaccinated } \\
\text { (self-reported) }\end{array}$}} & \multicolumn{4}{|c|}{ Seropositive $^{b}$} & \multicolumn{4}{|c|}{ Seropositive $^{c}$} \\
\hline & & & & & & \multicolumn{2}{|c|}{$\begin{array}{l}\text { Anti-SARS- } \\
\text { CoV-2 S protein }\end{array}$} & \multicolumn{2}{|c|}{$\begin{array}{l}\text { Anti-SARS- } \\
\text { CoV-2 N } \\
\text { protein }\end{array}$} & \multicolumn{2}{|c|}{$\begin{array}{c}\text { Antibodies of any } \\
\text { origin }\end{array}$} & \multicolumn{2}{|c|}{$\begin{array}{c}\text { Antibodies of } \\
\text { infectious origin }\end{array}$} \\
\hline & & $\mathrm{n}$ & $\%$ & $\mathrm{n}$ & $\%$ & $\mathrm{n}$ & $\%$ & $n$ & $\%$ & $\%$ & $95 \% \mathrm{Crl}$ & $\%$ & $95 \% \mathrm{Crl}$ \\
\hline & & 3,355 & 100 & 1,449 & 43.2 & 2,161 & 64.4 & 906 & 27.0 & 66.1 & $64.1-68.0$ & 29.9 & $28.0-31.9$ \\
\hline \multirow{2}{*}{ Sex } & Male & 1,541 & 45.9 & 669 & 43.4 & 995 & 64.6 & 416 & 27.0 & 65.4 & $62.8-68.1$ & 30.4 & $28.0-33.0$ \\
\hline & Female & 1,814 & 54.1 & 780 & 43.0 & 1,166 & 64.3 & 490 & 27.0 & 66.7 & $64.3-69.1$ & 29.5 & $27.2-31.9$ \\
\hline \multirow{9}{*}{$\begin{array}{l}\text { Age group } \\
\text { (years) }\end{array}$} & $0-5$ & 150 & 4.5 & 0 & 0 & 32 & 21.3 & 29 & 19.3 & 20.8 & $15.5-26.7$ & 20.8 & $15.5-26.7$ \\
\hline & $6-11$ & 281 & 8.4 & 0 & 0 & 100 & 35.6 & 95 & 33.8 & 31.4 & $26.7-36.4$ & 31.4 & $26.7-36.4$ \\
\hline & $12-17$ & 266 & 7.9 & 5 & 1.9 & 99 & 37.2 & 91 & 34.2 & 41.0 & $35.6-46.4$ & 37.7 & $32.5-43.1$ \\
\hline & $18-24$ & 300 & 8.9 & 85 & 28.3 & 187 & 62.3 & 107 & $35 \cdot 7$ & 63.6 & $57.3-69.8$ & 41.8 & $36.3-47.5$ \\
\hline & $25-34$ & 372 & 11.1 & 121 & 32.5 & 212 & 57.0 & 97 & 26.1 & 61.1 & $56.1-65.9$ & 31.9 & $27.8-36.2$ \\
\hline & $35-49$ & 805 & 24.0 & 323 & 40.1 & 505 & 62.7 & 219 & 27.2 & 64.4 & $60.2-68.6$ & 32.2 & $28.7-35.9$ \\
\hline & $50-64$ & 732 & 21.8 & 517 & 70.6 & 609 & 83.2 & 196 & 26.8 & 84.7 & $81.1-88.1$ & 29.8 & $26.5-33.4$ \\
\hline & $65-74$ & 207 & 6.2 & 174 & 84.1 & 187 & 90.3 & 41 & 19.8 & 89.2 & $84.2-93.4$ & 22.5 & $17.0-28.4$ \\
\hline & $\geq 75$ & 242 & 7.2 & 224 & 92.6 & 230 & 95.0 & 31 & 12.8 & 93.1 & $89.6-96.0$ & 16.2 & $11.8-21.1$ \\
\hline \multirow{3}{*}{$\begin{array}{l}\text { Education } \\
\text { leveld }^{d}\end{array}$} & Primary & 203 & 8.1 & 100 & 49.3 & 135 & 66.5 & 53 & 26.1 & 71.9 & $68.4-75.5$ & 29.7 & $26.6-33.1$ \\
\hline & Secondary & 818 & 32.5 & 393 & 48.0 & 560 & 68.5 & 219 & 26.8 & 70.3 & $64.1-76.5$ & 27.9 & $22.0-33.9$ \\
\hline & Tertiary & 1,499 & 59.5 & 878 & 58.6 & 1,134 & 75.7 & 381 & 25.4 & 75.2 & $72.6-77.9$ & 31.7 & $28.9-34.4$ \\
\hline
\end{tabular}

Crl: credible interval; N: nucleocapsid protein; S: spike protein; SARS-CoV-2: severe acute respiratory syndrome coronavirus 2.

a Self-reported having received at least one dose of the COVID-19 vaccine 14 days before blood sample was drawn.

b Serology based on Roche Elecsys anti-SARS-CoV-2 S immunoassay and N immunoassay (Roche Diagnostics, Rotkreuz, Switzerland), respectively.

Seroprevalence estimates reported as \% and 95\% credible interval, adjusted for test performance of both immunoassays and post-stratified to account for age distribution in the Geneva general population and for household clustering of infection and vaccination, $\mathrm{n}=3,355$ for total and sex- and age-stratified estimates; $n=2,520$ for education-stratified estimates, excluding participants aged $<18$ years. Seroprevalence of antibodies of any origin is based on proportion of participants with any anti-SARS-CoV-2 antibodies; seroprevalence of antibodies of infectious origin is based on proportion of participants who were naturally infected (but could also have been vaccinated).

d Self-reported education level among participants aged $\geq 18$ years $(n=2,520)$; missing education level values by age groups: ( $n=15)$ in the group of 18-24-year-olds; $(n=49)$ in the group of $25-44$-year-olds; $(n=53)$ in the group of 45-64-year-olds; ( $n=2)$ in the group of $65-74$-year-olds; and $(n=19)$ in the group of $\geq 75$-year-olds.

\section{Methods}

\section{Study design}

We conducted a cross-sectional serosurvey between 1 June and 7 July 2021, recruiting participants from a random sample of individuals aged $0-64$ years provided by the Swiss Federal Office of Statistics and an ageand sex-stratified random sample of individuals aged 18-24 years and $\geq 50$ years from a previous serosurvey using the same methodology $[5,7]$. Newly selected individuals (aged 0-64 years) were invited by letter, while returning individuals (aged $\geq 18$ years) were invited by letter or email when available. Individuals not having responded to the first invitation received up to two written reminders and were contacted by phone when available. Children and teenagers (aged $<18$ years) were invited to participate alongside members of their household, while adults received individual invitations. Participation rates differed between age groups and depending on previous participation, ranging from $18.9 \%$ for newly-recruited children aged $<6$ years (overall $23.7 \%$ participation rate among newly invited individuals) to $80.0 \%$ for returning participants aged $\geq 65$ years $(78.0 \%$ overall participation rate among returning participants) (Supplementary Figure S1). During the visit, participants provided a venous blood sample and completed a questionnaire that collected sociodemographic data, COVID-19-related medical history and vaccination information (Supplement $\mathrm{S}_{1}$ ).

\section{Immunoassays}

To detect anti-SARS-CoV-2 antibodies, we used two commercially-available immunoassays: the Roche Elecsys anti-SARS-CoV-2 S immunoassay (Roche Diagnostics, Rotkreuz, Switzerland), which detects immunoglobulins ( $\mathrm{gG} / \mathrm{A} / \mathrm{M})$ against the receptor binding domain of the virus spike (S) protein (\#09 289 275190 , Roche-S), and has an in-house sensitivity of 99.6\% (95\% confidence interval (Cl): 98.3-100) and specificity of $99.8 \%(95 \% \mathrm{Cl}: 99.3-100)$ [8,9]; and the Roche Elecsys anti-SARS-CoV-2 N immunoassay (Roche Diagnostics), which detects immunoglobulins (IgG/A/M) targeting the virus nucleocapsid (N) protein (\#09 203079 190, Roche-N), and has an in-house sensitivity of $99.8 \%(95 \% \mathrm{Cl}: 99.4-100)$ and specificity of 99.1\% (95\% Cl: 98.3-99.7) [8]. We defined seropositivity using the manufacturer's provided cut-off value of 
Confirmed SARS-CoV-2 infections and estimated seroprevalence of anti-SARS-CoV-2 antibodies, Geneva, Switzerland, March 2020-July 2021
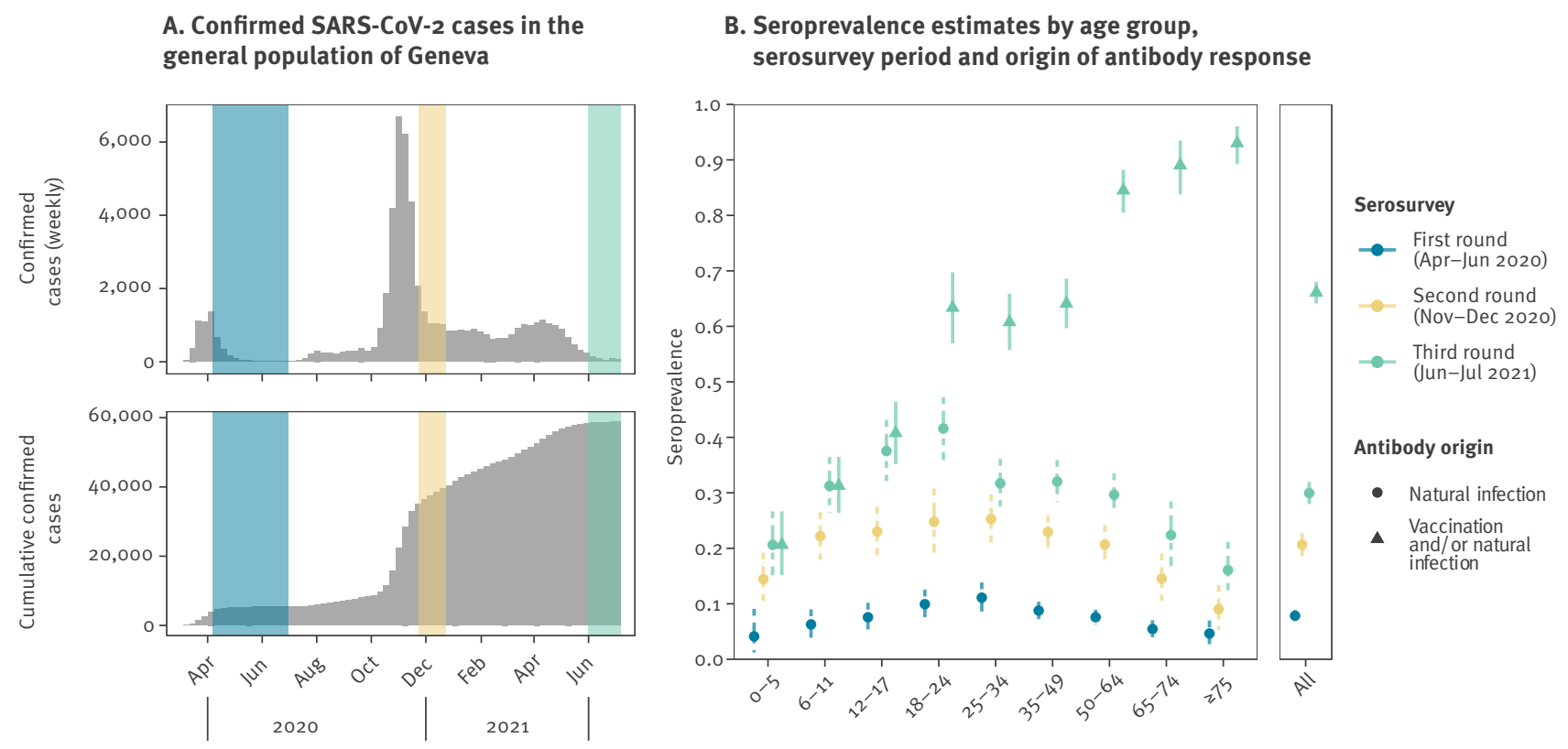

SARS-CoV-2: severe acute respiratory syndrome coronavirus 2.

A. Data presented in grey (available from: https://infocovid.smc.unige.ch) and serosurvey timings (coloured shaded). First serosurvey AprilJune 2020 (blue), in which the group of 0-5-year-olds only included children aged 5 years [7]; second serosurvey November-December 2020 (yellow) [5]; and third serosurvey June-July 2021 (green). B. Colour shades indicate timing of the serosurvey: first serosurvey April-June 2020 (blue), in which the group of 0-5-year-olds only included children aged 5 years [7]; second serosurvey November-December 2020 (yellow) [5] and third serosurvey June-July 2021 (green). Symbols indicate the antibody origin: dot indicates antibodies developed after infection (during the first two serosurveys, which took place before vaccination became available (see Figure 1), infection was the only possible antibody origin); triangle indicates antibodies developed after infection and/or vaccination. Vertical bars represent $95 \%$ credible intervals in seroprevalence estimations.

titer $\geq 0.8 \mathrm{U} / \mathrm{mL}$ for the Roche-S and cut-off index $\geq 1.0$ for the Roche-N immunoassays.

\section{Statistical analyses}

To estimate seroprevalence (\% and 95\% credible interval $(\mathrm{Crl})$ ), we expanded previous Bayesian modelling frameworks that accounted for age, sex, immunoassay performance and household clustering [5,7], jointly modelling the antibody response measured by the two immunoassays while additionally accounting for vaccination information. Since the vaccines used to date in Geneva elicit no response to the SARS-CoV-2 N protein [10], we used participants' two-marker antibody profiles to estimate the proportion having any anti-SARSCoV-2 antibody and the proportion having antibodies because of infection (but could also have been vaccinated). Full details of the statistical model are provided in the Supplement $S_{1}$.

To investigate potential socioeconomic disparities in seroprevalence, we estimated seroprevalence according to the highest obtained educational level among participants aged $\geq 18$ years, and calculated the corresponding prevalence ratios and $95 \% \mathrm{Crl}$. We applied the probabilistic programming language Stan using the Rstan package and R version 4.1 (R Foundation, Vienna, Austria) [11].

\section{Ethical statement}

The Geneva Cantonal Commission for Research Ethics approved this study (Project number 2020-00881). Informed written consent was obtained from all participants.

\section{Results}

We included 3,355 participants, 2,497 first-time participants and 858 returning participants, of whom $54.1 \%$ were women, $20.8 \%$ were aged $<18$ years and $13.4 \%$ were aged $\geq 65$ years. Among adults, $8.1 \%$ had a primary education level and $59.5 \%$ had a tertiary education level (Table 1). Compared with the general population of Geneva, our sample had an overrepresentation of individuals with a tertiary education level (Supplementary Table $\mathrm{S}_{1}$ ).

Anti-SARS-CoV-2 antibodies were detected in all but three participants reporting having received at least one dose of the COVID-19 vaccine more than 14 days before serological assessment. Overall, $43.2 \%$ reported having received at least one COVID-19 vaccine dose $>14$ days before their blood draw, $64.4 \%$ of all participants tested positive for anti-S antibodies, and $27.0 \%$ tested positive for anti-N antibodies (Table 1). The proportion of self-reported vaccinated participants was similar to that of the general population of Geneva across most 
TABLE 2

Prevalence ratio for seroprevalence of anti-SARS-CoV-2 antibodies, Geneva, Switzerland, 1 June-7 July 2021

\begin{tabular}{|c|c|c|c|c|c|c|c|c|}
\hline \multirow{2}{*}{\multicolumn{2}{|c|}{ Characteristics }} & \multirow{3}{*}{$\begin{array}{c}\text { Participants } \\
\text { n } \\
1,541 \\
\end{array}$} & \multicolumn{3}{|c|}{ Antibodies of any origin } & \multicolumn{3}{|c|}{ Antibodies of infectious origin } \\
\hline & & & \multirow{2}{*}{$\begin{array}{c}\begin{array}{c}\text { Prevalence } \\
\text { ratio }^{\mathrm{a}}\end{array} \\
1.01 \\
\end{array}$} & \multirow{2}{*}{$\begin{array}{c}\left.95 \% \mathrm{Cr}\right|^{\mathrm{a}} \\
0.94-1.08 \\
\end{array}$} & \multirow{2}{*}{$\begin{array}{c}p \text { value } \\
0.75\end{array}$} & \multirow{2}{*}{$\begin{array}{c}\begin{array}{c}\text { Prevalence } \\
\text { ratio }^{\mathrm{a}}\end{array} \\
1.01 \\
\end{array}$} & \multirow{2}{*}{$\begin{array}{l}95 \% \mathrm{Crl}^{\mathrm{a}} \\
0.92-1.11 \\
\end{array}$} & \multirow{2}{*}{$\begin{array}{c}\text { p value } \\
0.81 \\
\end{array}$} \\
\hline \multirow{2}{*}{ Sex } & Male & & & & & & & \\
\hline & Female & 1,814 & 1 & \multicolumn{2}{|c|}{ NA } & 1 & \multicolumn{2}{|c|}{ NA } \\
\hline \multirow{9}{*}{$\begin{array}{l}\text { Age group } \\
\text { (years) }\end{array}$} & $0-5$ & 150 & 0.34 & $0.25-0.44$ & $<0.0001$ & 0.65 & $0.48-0.85$ & 0.002 \\
\hline & $6-11$ & 281 & 0.52 & $0.43-0.61$ & $<0.0001$ & 0.99 & $0.81-1.20$ & 0.86 \\
\hline & $12-17$ & 266 & 0.67 & $0.57-0.78$ & $<0.0001$ & 1.19 & $0.98-1.42$ & 0.08 \\
\hline & $18-24$ & 300 & 1.04 & $0.92-1.17$ & 0.49 & 1.32 & $1.10-1.57$ & 0.003 \\
\hline & $25-34$ & 372 & 1 & \multicolumn{2}{|c|}{ NA } & 1 & \multicolumn{2}{|c|}{ NA } \\
\hline & $35-49$ & 805 & 1.06 & $0.96-1.16$ & 0.27 & 1.01 & $0.86-1.19$ & 0.89 \\
\hline & $50-64$ & 732 & 1.39 & $1.28-1.52$ & $<0.0001$ & 0.94 & $0.79-1.10$ & 0.43 \\
\hline & $65-74$ & 207 & 1.47 & $1.34-1.60$ & $<0.0001$ & 0.71 & $0.52-0.92$ & 0.01 \\
\hline & $\geq 75$ & 242 & 1.53 & $1.41-1.67$ & $<0.0001$ & 0.51 & $0.36-0.68$ & $<0.0001$ \\
\hline \multirow{3}{*}{$\begin{array}{l}\text { Education } \\
\text { level }^{\mathrm{b}}\end{array}$} & Primary & 203 & 0.85 & $0.77-0.93$ & $<0.0001$ & 0.93 & $0.81-1.07$ & 0.28 \\
\hline & Secondary & 818 & 0.84 & $0.72-0.96$ & 0.01 & 0.88 & $0.69-1.08$ & 0.22 \\
\hline & Tertiary & 1,499 & 1 & \multicolumn{2}{|c|}{ NA } & 1 & \multicolumn{2}{|c|}{ NA } \\
\hline
\end{tabular}

Crl: credible interval; NA: not applicable; SARS-CoV-2: severe acute respiratory syndrome coronavirus 2.

a Prevalence ratio ( $95 \% \mathrm{Crl}$ ) from Bayesian multinomial regression models accounting for sex, age, test performance and household clustering. Reference group for age and sex estimates $(n=3,355)$ is female, aged $25-34$ years. For education level estimates $(n=2,520)$, reference group is female, aged 25-44 years with tertiary education level.

${ }^{b}$ Self-reported education level among participants aged $\geq 18$ years $(n=2,520)$.

age groups; study participants aged $\geq 70$ years reported higher vaccination rates than their counterparts in the general population (Supplementary Table S2).

The overall seroprevalence estimate was $66.1 \%(95 \%$ Crl: 64.1-68.0), including a seroprevalence of $29.9 \%$ (95\% Crl: 28.0-31.9) for infection-derived antibodies (Figure 2). Estimates were similar across sexes, but varied widely across age groups, being lowest among children aged $0-5$ years (20.8\%; 95\% Crl: 15.5-26.7) and highest among older adults aged $\geq 75$ years (93.1\%; 95\% Crl: 89.6-96.0). In contrast, the seroprevalence of infection-induced antibodies was lowest among older adults aged $\geq 75$ years (16.2\%; 95\% Crl: $11.8-21.1$ ) and highest among young adults aged $18-24$ years $(41.8 \%$; 95\% Crl: 36.3-47.5) (Figure 2).

Among adults with tertiary education, 58.6\% reported receiving at least one COVID-19 vaccine dose (Table 1 and Supplementary Table S3). In this group, $75.7 \%$ had anti-S antibodies, and $25.4 \%$ had anti- $\mathrm{N}$ antibodies. Among adults with up to a primary education, $49.3 \%$ reported receiving at least one COVID-19 vaccine dose, $66.5 \%$ had anti-S antibodies and $26.1 \%$ had anti- $\mathrm{N}$ antibodies. The overall seroprevalence was 75.2\% (95\% Crl: 72.6-77.9) among adult participants with tertiary education and $71.9 \%$ (95\% Crl: 68.4-75.5) among those with up to a primary education (Table 1); the corresponding prevalence ratio for overall antibody seroprevalence was 0.85 (95\% Crl: 0.77-0.93) among participants with up to primary education relative to those with a tertiary education level (Table 2 ).

\section{Discussion}

In this seroprevalence survey we found that, by 7 July $2021,66.1 \%$ of the population in Geneva had developed antibodies against SARS-CoV-2 after vaccination and/or infection. We also found that $29.9 \%$ of the population had antibodies following infection with SARS-CoV-2, three times more than the seroprevalence of $10.8 \%$ reported in April-June 2020 [7], and an $8.8 \%$ increase from the $21.1 \%$ seroprevalence reported in November-December, 2020 [5] (Supplementary Table S4). This increase in seroprevalence of infectioninduced antibodies within a 6-month period was largest among young adults aged $18-24$ years (16.1\% increase) and teenagers aged $12-17$ years (14.1\% increase), indicating the third COVID-19 wave, comprised primarily of the Alpha (B.1.1.7) variant [12], may have particularly affected these age groups.

This is the first serosurvey providing seroprevalence estimates after the widespread availability of vaccination. We observed marked age differences in seroprevalence, which closely reflect the age-related infection risk observed in Geneva and elsewhere throughout the pandemic $[5,7,13]$ and, subsequently, the progression of the age-dependent vaccination eligibility since December 2020 [14]. For instance, the $20.8 \%$ seroprevalence in children aged $0-5$ years represents a $5.9 \%$ increase in a 6 -month period which may indicate 
a lower infection risk compared to adults, and the fact that, to date, vaccination in Switzerland remains approved only for individuals aged $\geq 12$ years. The $16.2 \%$ seroprevalence of infection-induced antibodies in adults aged $\geq 75$ years mirrors their previously reported lower infection risk $[5,7]$ and the fact that they were the first age group targeted by the vaccination campaign; with a reported $92.6 \%$ vaccination rate and an associated estimated total seroprevalence of $93.1 \%$. It is also not possible to exclude that the lower proportion of participants with infection-induced antibodies in this age group is attributable to immunosenescence or higher likelihood of antibodies waning in the elderly population $[15,16]$.

We also found that vaccination uptake differed by education level, with a higher proportion of individuals with tertiary education reporting being vaccinated than individuals with lower education levels, reflecting socioeconomic inequalities in vaccination as reported in the US and Israel $[17,18]$. The proportion having anti$\mathrm{S}$ antibodies was correspondingly higher among individuals with tertiary education, though the proportion of anti-N antibodies was similar across education level groups, reflecting findings from a previous seroprevalence study [19], but differing from patterns of socioeconomic inequalities in infection risk observed in the United Kingdom, Germany and the US [20-22]. While a previous survey found no evidence of socioeconomic inequalities in infection-induced anti-SARS-CoV-2 antibody seroprevalence in the Geneva population [19], this study has indicated emerging inequalities in overall seroprevalence, likely driven by the higher vaccination uptake among the more socioeconomically privileged individuals. Indeed, several studies have found a clear pattern of socioeconomic disparities in vaccine hesitancy, whereby a lower proportion of socioeconomically disadvantaged individuals report intention or willingness to get vaccinated against COVID-19 than do more socioeconomically privileged individuals [23-28].

Strengths of this study include a large sample that is broadly representative of the general population in Geneva, the measurement of antibodies against both the SARS-CoV-2 S and N proteins and the robust novel modelling framework. Limitations include the fact that, as with most surveys [29], the sample population was generally more socioeconomically advantaged than the general population (Supplement S1), which may have led to overestimation of vaccine-derived antibody seroprevalence. However, the proportion of vaccinated individuals in our sample was similar to that observed in the general population of Geneva (Supplementary Table S2). Another limitation was that we only included formal residents and that we only assessed education as a socioeconomic indicator, which may have precluded the identification of inequalities based on other indicators. Finally, since we did not perform neutralisation assays, our estimates may not completely reflect protective immunity against SARS-CoV-2 [30].

\section{Conclusion}

This study provides seroprevalence estimates of antiSARS-CoV-2 antibodies in a broadly representative sample of the general population in Geneva after the third pandemic wave and the start of mass vaccination, distinguishing between antibodies developed following vaccination and/or infection, and antibodies developed following infection only. Our findings highlight how mass vaccination has closed the immunity gap in most of the adult population, particularly among older individuals who are at the greatest risk of severe COVID-19 outcomes. They attest to the effectiveness of free-of-charge vaccination programs in promoting immunisation against the virus while highlighting the need to strengthen efforts to address vaccine hesitancy. Importantly, our findings also show that the majority of children and teenagers, and a considerable proportion of young and middle-aged adults, lack antiSARS-CoV-2 antibodies, leaving behind a large reservoir in the population to sustain transmission in the critical months to come. Finally, our findings indicate the emergence of socioeconomic inequalities in seroprevalence of anti-SARS-CoV-2 antibodies, likely driven by socioeconomically-related vaccine uptake.

Acknowledgements

Specchio-COVID19 study group

Isabelle Arm-Vernez, Andrew S Azman, Fatim Ba, Oumar $\mathrm{Ba}$, Delphine Bachmann, Jean-François Balavoine, Michael Balavoine, Hélène Baysson, Lison Beigbeder, Julie Berthelot, Patrick Bleich, Gaëlle Bryand Rumley, François Chappuis, Prune Collombet, Delphine Courvoisier, Alain Cudet, Carlos de Mestral, Paola D'ippolito, Richard Dubos, Roxane Dumont, Isabella Eckerle, Nacira El Merjani, Antoine Flahault, Natalie Francioli, Marion Frangville, Idris Guessous, Séverine Harnal, Samia Hurst, Laurent Kaiser, Omar Kherad, Julien Lamour, Pierre Lescuyer, François L'Huissier, FannyBlanche Lombard, Andrea Jutta Loizeau, Elsa Lorthe, Chantal Martinez, Lucie Ménard, Lakshmi Menon, Ludovic MetralBoffod, Benjamin Meyer, Alexandre Moulin, Mayssam Nehme, Natacha Noël, Francesco Pennacchio, Javier PerezSaez, Giovanni Piumatti, Didier Pittet, Jane Portier, Klara M Posfay-Barbe, Géraldine Poulain, Caroline Pugin, Nick Pullen, Zo Francia Randrianandrasana, Aude Richard, Viviane Richard, Frederic Rinaldi, Jessica Rizzo, Khadija Samir, Claire Semaani, Silvia Stringhini, Stéphanie Testini, Didier Trono, Guillemette Violot, Nicolas Vuilleumier, Ania Wisniak, Sabine Yerly, María-Eugenia Zaballa.

This study would not have been possible without the passionate work of the Higher College of Education in Health (HEdS) students who chose this project for their internship (Marjourie Albarenga, Deborah Amrein, Mayra Battisti, Tatyana Butter, Milica Colovic, Witoria Distinto, Marvorid Jamshedzoda and Nicolas Lechaud), the civil service agents (Vladimir Davidovic and Aniss Moussa), the medical students (Joséphine Duc, Aurélia Hepner, Hugo-Ken Oulevey, Irine Sakvarelidze and Nawel Tounsi) and the caregiver Shamso Hussen. We thank the Hôpital de La Tour and the Clinique de Carouge, as well as the Division of Pediatrics, HUG, for allowing us to use their premises for recruitment. We are deeply grateful to Dr Cyril Sahyoun and his team for our enriching collaboration aimed at easing the experience of children during blood sampling. Finally, we thank all the 
participants for their interest and invaluable contribution to the study.

Funding: Swiss Federal Office of Public Health, the General Directorate of Health of the Department of Safety, Employment and Health of the canton of Geneva, the Private Foundation of the Geneva University Hospitals, the Swiss School of Public Health (Corona Immunitas Research Program) and the Fondation des Grangettes.

\section{Conflict of interest}

None declared.

\section{Authors' contributions}

IG, SS, MEZ, NP, JPS, FP, AW, RD, HB, VR, KPB, EL, LK, CS, FC, $D P, J F B, J L, A L, O K, A S A$ and NV designed the study and/or acquired data. NP, JPS and ASA conducted statistical analyses and created graphics. CdM conducted literature review, wrote the first draft of the manuscript and created tables. All authors contributed to the interpretation of results and read and approved the final manuscript. IG, SS, MEZ, NP and JPS had full access to all data in the study, and the corresponding author had final responsibility for decision to submit for publication.

\section{References}

1. Campbell F, Archer B, Laurenson-Schafer H, Jinnai Y, Konings F, Batra N, et al. Increased transmissibility and global spread of SARS-CoV-2 variants of concern as at June 2021. Euro Surveill. 2021;26(24):2100509. https://doi.org/10.2807/1560-7917. ES.2021.26.24.2100509 PMID: 34142653

2. European Centre for Disease Prevention and Control (ECDC). COVID-19 vaccine rollout report week 33. Stockholm: ECDC; 2021. Available from: https://covid19-vaccine-report.ecdc. europa.eu/

3. Murhekar MV, Clapham H. COVID-19 serosurveys for public health decision making. Lancet Glob Health. 2021;9(5):e5596o. https://doi.org/10.1016/S2214-109X(21)00057-7 PMID: 33705691

4. République et Canton de Genève (Republic and Canton of Geneva). COVID-19 à Genève. Données cantonales [COVID-19 in Geneva. Cantonal data]. Geneva: Republic and Canton of Geneva. [Accessed: 11 Aug 2021]. French. Available from: https://infocovid.smc.unige.ch

5. Stringhini S, Zaballa M-E, Perez-Saez J, Pullen N, de Mestral C, Picazio A, et al. Seroprevalence of anti-SARS-CoV-2 antibodies after the second pandemic peak. Lancet Infect Dis. 2021;21(5):600-1. https://doi.org/10.1016/S14733099(21)00054-2 PMID: 33539733

6. Canto e Castro L, Gomes A, Serrano M, Pereira AH, Ribeiro R, Napoleão P, et al. Longitudinal SARS-CoV-2 seroprevalence in Portugal and antibody maintenance 12 months after the start of the COVID-19 pandemic. Research Square.2021; Preprint. https://doi.org/10.21203/rs.3.rs-603060/v1

7. Stringhini S, Wisniak A, Piumatti G, Azman AS, Lauer $\mathrm{SA}$, Baysson $\mathrm{H}$, et al. Seroprevalence of anti-SARS-CoV-2 IgG antibodies in Geneva, Switzerland (SEROCoV-POP): a population-based study. Lancet. 2020;396(10247):3139. https://doi.org/10.1016/S0140-6736(20)31304-0 PMID: 32534626

8. Perez-Saez J, Zaballa M-E, Yerly S, Andrey DO, Meyer B, Eckerle I, et al. Persistence of anti-SARS-CoV-2 antibodies: immunoassay heterogeneity and implications for serosurveillance. Clin Microbiol Infect. 2021;S1198743X(21)00371-2. https://doi.org/10.1016/j.cmi.2021.06.040 PMID: 34245905

9. L'Huillier AG, Meyer B, Andrey DO, Arm-Vernez I, Baggio $S$, Didierlaurent A, et al. Antibody persistence in the first 6 months following SARS-CoV-2 infection among hospital workers: a prospective longitudinal study. Clin Microbiol Infect. 2021;27(5):784.e1-8. https://doi.org/10.1016/j. cmi.2021.01.005 PMID: 33482352

10. Wheeler SE, Shurin GV, Yost M, Anderson A, Pinto L, Wells A, et al. Differential antibody response to mRNA COVID-19 vaccines in healthy subjects. Microbiol Spectr. 2021;9(1):eoo34121. https://doi.org/10.1128/Spectrum.00341-21 PMID: 34346750

11. Stan Development Team. Rstan: the R interface to Stan. R package version 2.21.2. 2020. Available from: https://mc-stan. org

12. European Centre for Disease Prevention and Control (ECDC). SARS-CoV-2-increased circulation of variants of concern and vaccine rollout in the EU/EEA, 14th update. Stockholm: ECDC; 2021. Available from: https://www.ecdc.europa.eu/sites/ default/files/documents/RRA-15th-update-June\%202021.pdf

13. Bajema KL, Wiegand RE, Cuffe K, Patel SV, Iachan R, Lim T, et al. Estimated SARS-CoV-2 seroprevalence in the US as of September 2020. JAMA Intern Med. 2021;181(4):450-60. https://doi.org/10.1001/jamainternmed.2020.7976 PMID: 33231628

14. République et Canton de Genève (Republic and Canton of Geneva). Vaccination in Geneva: numbers and campaign in Geneva. Geneva: Republic and Canton of Geneva. [Accessed: 15 Jul 2021]. Available from: https://www.ge.ch/en/node/23804

15. Bartleson IM, Radenkovic D, Covarrubias AJ, Furman D, Winer DA, Verdin E. SARS-CoV-2, COVID-19 and the aging immune system. Nat Aging.2021;1(9):769-82. https://doi.org/10.1038/ S43587-021-00114-7

16. Collier DA, Ferreira IATM, Kotagiri P, Datir RP, Lim EY, Touizer E, et al. Age-related immune response heterogeneity to SARSCoV-2 vaccine BNT162b2. Nature. 2021;596(7872):417-22. https://doi.org/10.1038/s41586-021-03739-1 PMID: 34192737

17. Barry V, Dasgupta S, Weller DL, Kriss JL, Cadwell BL, Rose C, et al. Patterns in COVID-19 vaccination coverage, by social vulnerability and urbanicity - United States, December 14, 2020-May 1, 2021. MMWR Morb Mortal Wkly Rep. 2021;70(22):818-24. https://doi.org/10.15585/mmwr. mm7022e1 PMID: 34081685

18. Caspi G, Dayan A, Eshal Y, Liverant-Taub S, Twig G, Shalit U, et al. Socioeconomic disparities and COVID-19 vaccination acceptance: a nationwide ecologic study. Clin Microbiol Infect. 2021;27(10):1502-6. https://doi.org/10.1016/j.cmi.2021.05.030 PMID: 34111591

19. Richard A, Wisniak A, Perez-Saez J, Garrison-Desany H, Petrovic D, Piumatti G, et al. Seroprevalence of anti-SARSCoV-2 IgG antibodies, risk factors for infection and associated symptoms in Geneva, Switzerland: a population-based study. Scand J Public Health. 2021;14034948211048050. PMID: 34664529

20. Niedzwiedz CL, O’Donnell CA, Jani BD, Demou E, Ho FK, Celis-Morales $C$, et al. Ethnic and socioeconomic differences in SARS-CoV-2 infection: prospective cohort study using UK Biobank. BMC Med. 2020;18(1):160. https://doi.org/10.1186/ S12916-020-01640-8 PMID: 32466757

21. Wachtler B, Michalski N, Nowossadeck E, Diercke M, Wahrendorf M, Santos-Hövener C, et al. Socioeconomic inequalities in the risk of SARS-CoV-2 infection - First results from an analysis of surveillance data from Germany. J Health Monit.2020;S7:18-29. https://doi.org/10.25646/7057

22. Clouston SAP, Natale G, Link BG. Socioeconomic inequalities in the spread of coronavirus-19 in the United States: A examination of the emergence of social inequalities. Soc Sci Med. 2021;268:113554. https://doi.org/10.1016/j. socscimed.2020.113554 PMID: 33308911

23. Wisniak A, Baysson H, Pullen N, Nehme M, Pennacchio F, Zaballa M-E, et al. COVID-19 vaccination acceptance in the canton of Geneva: a cross-sectional population-based study. medRxiv. 2021;2021.07.05.21260024. Preprint.

24. Paul E, Steptoe A, Fancourt D. Attitudes towards vaccines and intention to vaccinate against COVID-19: Implications for public health communications. Lancet Reg Health Eur. 2021;1:100012. https://doi.org/10.1016/j.lanepe.2020.100012 PMID: 33954296

25. Sonawane K, Troisi CL, Deshmukh AA, COVID-19 vaccination in the UK: Addressing vaccine hesitancy. Lancet Reg Health Eur. 2021;1:100016. https://doi.org/10.1016/j.lanepe.2020.100016 PMID: 34173622

26. Viswanath K, Bekalu M, Dhawan D, Pinnamaneni R, Lang J, McLoud R. Individual and social determinants of COVID-19 vaccine uptake. BMC Public Health. 2021;21(1):818. https:// doi.org/10.1186/s12889-021-10862-1 PMID: 33910558

27. Rhodes A, Hoq M, Measey M-A, Danchin M. Intention to vaccinate against COVID-19 in Australia. Lancet Infect Dis. 2021;21(5):e110. https://doi.org/10.1016/S14733099(20)30724-6 PMID: 32941786

28. Peretti-Watel P, Seror V, Cortaredona S, Launay O, Raude J, Verger $\mathrm{P}$, et al. A future vaccination campaign against COVID-19 at risk of vaccine hesitancy and politicisation. Lancet Infect Dis. 2020;20(7):769-70. https://doi.org/10.1016/S14733099(20)30426-6 PMID: 32445713 
29. Accorsi EK, Qiu X, Rumpler E, Kennedy-Shaffer L, Kahn R,

Joshi K, et al. How to detect and reduce potential sources of biases in studies of SARS-CoV-2 and COVID-19. Eur J Epidemiol. 2021;36(2):179-96. https://doi.org/10.1007/s10654-021-007277 PMID: 33634345

30. Chia WN, Zhu F, Ong SWX, Young BE, Fong S-W, Le Bert N, et al. Dynamics of SARS-CoV-2 neutralising antibody responses and duration of immunity: a longitudinal study. Lancet Microbe. 2021;2(6):e240-9. PMID: 33778792

\section{License, supplementary material and copyright}

This is an open-access article distributed under the terms of the Creative Commons Attribution (CC BY 4.0) Licence. You may share and adapt the material, but must give appropriate credit to the source, provide a link to the licence and indicate if changes were made.

Any supplementary material referenced in the article can be found in the online version.

This article is copyright of the authors or their affiliated institutions, 2021. 